\title{
Abdominal Cocoon: A Rare Entity
}

\author{
Nouf Akeel, Majid Mansouri, Nisar Haider Zaidi \\ Department of Surgery, King Abdulaziz University Hospital, Jeddah, Saudi Arabia \\ Email: drnhzaidi@hotmail.com
}

Received 24 July 2014; revised 20 August 2014; accepted 2 September 2014

Copyright (C) 2014 by authors and Scientific Research Publishing Inc.

This work is licensed under the Creative Commons Attribution International License (CC BY).

http://creativecommons.org/licenses/by/4.0/

(c) (i) Open Access

\begin{abstract}
Background: Abdominal cocoon is a rare disease where small intestine is enclosed in a membrane and commonly presents with features of bowel obstruction. Case Reports: We present two cases: one 28 years old male presented with abdominal pain and was diagnosed as abdominal cocoon at laparotomy; and another 81 years old female, a case of sigmoid cancer, was diagnosed at laparotomy as abdominal cocoon. In both cases membrane enclosing small intestine was excised. Histopathology of membrane was reported as fibro-collagenous tissue. Discussion: Abdominal cocoon is a rare entity, and its etiology is poorly understood. In most of cases preoperative diagnosis is not made with certainty despite of advancement in imaging. So, most of cases are diagnosed at laparotomy. Excision of membrane is the definitive treatment of abdominal cocoon. Conclusion: A high index of suspicion is required for diagnosing abdominal cocoon.
\end{abstract}

\section{Keywords}

Abdominal Cocoon, Sclerosing Encapsulating Peritonitis, Ideopathic

\section{Introduction}

Abdominal cocoon is thickened peritoneum which encases a part or all of small bowel, thus looking like cocoon. This condition was first reported by Foo et al. [1] in 10 young girls with symptoms of bowel obstruction two years after menarche. He postulated that retrograde menstruation caused chemical peritonitis leading to the formation of a cocoon. Similar condition was described by Owtschinnikow in 1907 as "peritonitis chronica fibrosa incapsulata" [2]. It is known by different names like encapsulating peritonitis, peritonitis chronic fibrosa incapsulata or sclerosing encapsulating peritonitis (SEP). It commonly presents as intestinal obstruction, weight loss or abdominal mass and in some cases it may be asymptomatic. A number of theories have been put forward to explain its causative agents but exact etiology is yet unknown. Most cases are diagnosed incidentally at laparotomy. We present two cases of abdominal cocoon. 


\section{Case Reports}

\subsection{Case 1}

28 years old male patient came to the ER on 26/11/2010 with the complaints of periumbilical pain associated with nausea, vomiting and constipation for 4 days duration. No fever or weight loss. On examination, he was hemodynamically stable (T: 36.6, BP: 148/86, P: 86, RR: 36) His abdomen was markedly distended with localized tenderness over periumbilical region. Bowel sounds were sluggish. PR examination revealed empty rectum. All his laboratory workup were within normal limits. Chest $\mathrm{X}$ ray showed no air under diaphragm. Erect and supine abdominal $\mathrm{X}$ rays showed multiple air fluid levels and dilated small bowel. CT abdomen pelvis was done and showed distended jejunal and ileal loops with collapsed distal ileum (Figure 1) and collapsed colon with free fluid in mesentery. The appearance was suggestive of adhesions with small bowel obstruction (Figure 2).

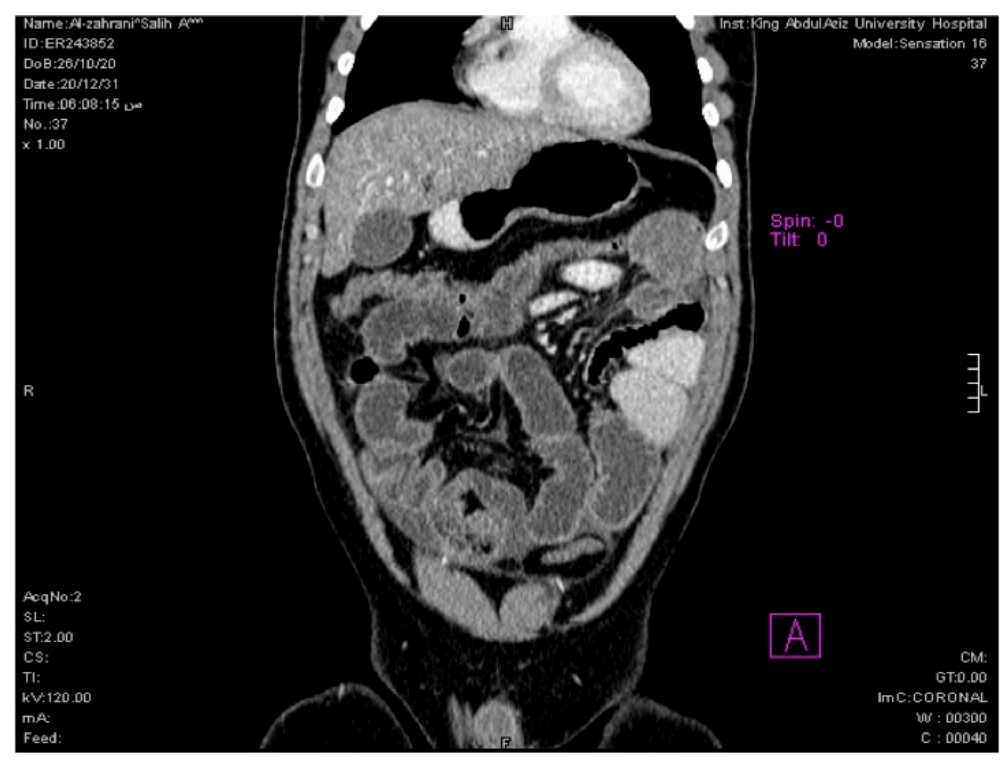

Figure 1. CT scan of abdomen showing thickened adherent dilated small bowel loops.

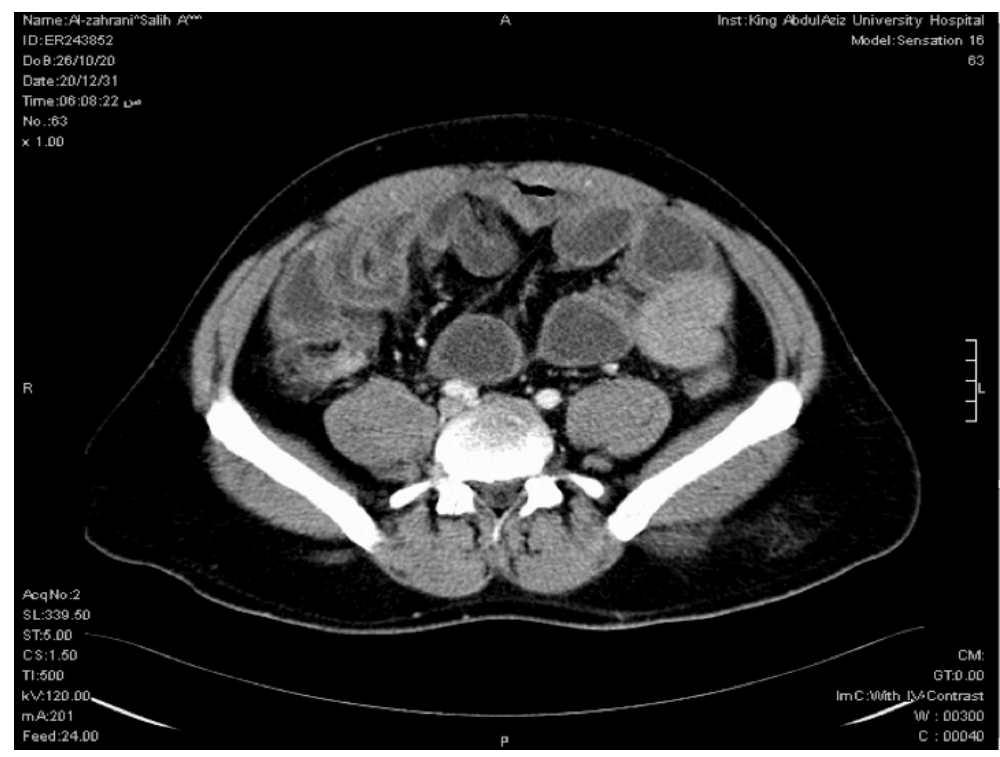

Figure 2. CT scan abdomen showing thickened small bowel with fat stranding. 
The patient was admitted. Emergency laparoscopic exploration was done which showed tough, partially transparent bag-like membrane engulfing about 3 feet of amalgamated terminal ileal loops. The membrane was partially excised and flimsy adhesions between bowel loops were divided. Appendectomy was done. His post operative period was uneventful and was discharged in good health. Histopathological examination of the excised membrane showed fibrocollagenous tissue.

\subsection{Case 2}

81 years old female patient was electively admitted for sigmoid cancer resection. Her past medical history includes diabetes, hypertension and atrial fibrillation. On examination she was vitally stable. Per abdominal examination showed mass left iliac foss a which was non tender. She was diagnosed as a case of sigmoid mass and was prepared for surgery. Laparotomy revealed distal ileal loops and cecum enveloped by thick fibrous membrane (Figure 3 and Figure 4) and was diagnosed per-operatively as a case of abdominal cocoon. Excision of membrane around small bowel was done with Sigmoid colectomy. Appendectomy was done TO avoid any diagnostic dilemma in future if patient present with right lower abdominal pain. Biopsy from the membrane was taken which showed fibro-collagenous membrane which confirmed the diagnosis of abdominal cocoon.

\section{Discussion}

Sclerosing encapsulating peritonitis may be primary or idiopathic and secondary when it has a definitive cause.

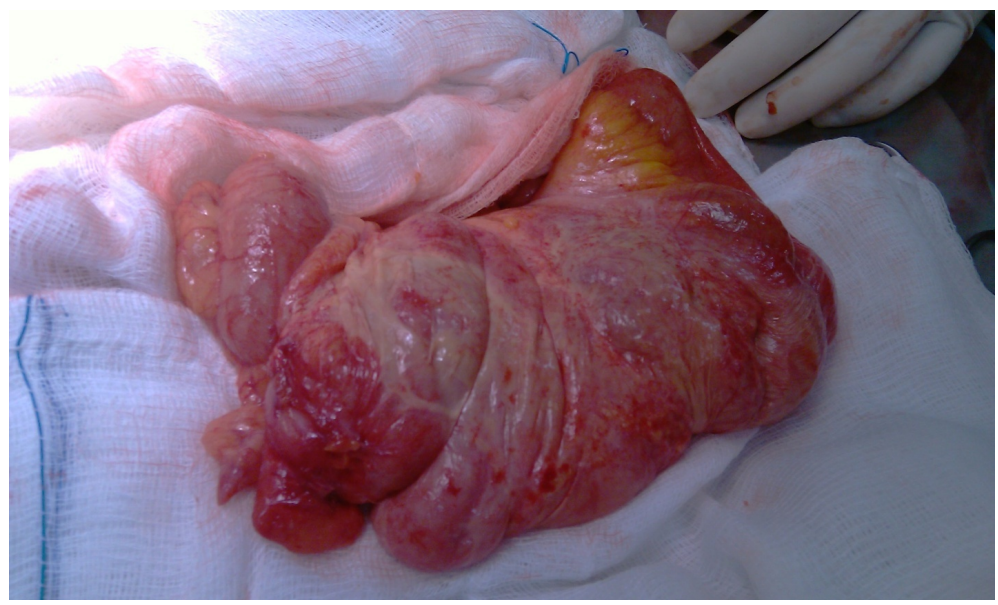

Figure 3. Abdominal cocoon, a membrane covering small intestine.

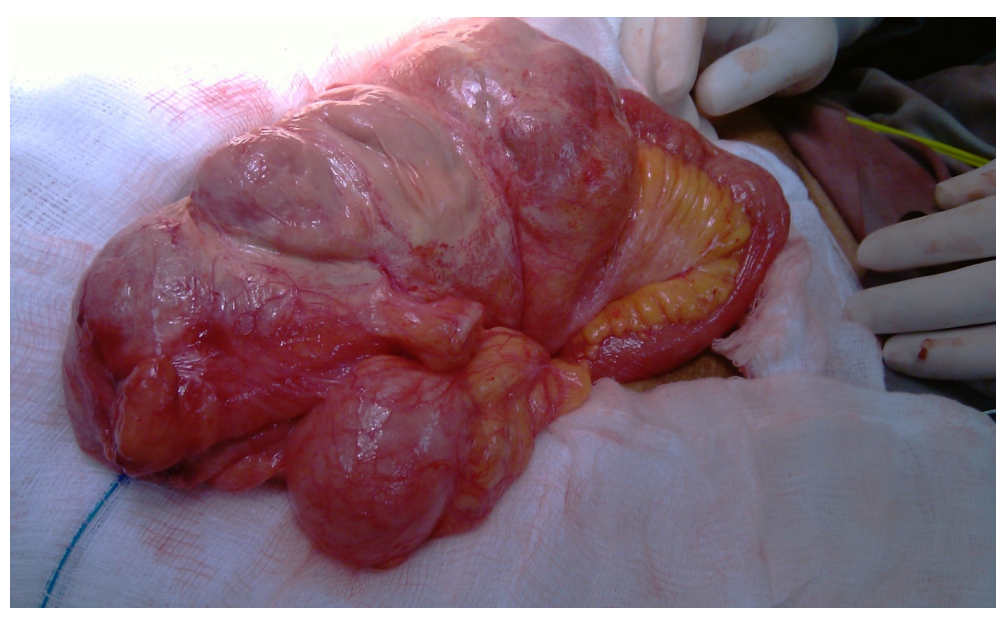

Figure 4. Tough fibrous membrane covering terminal ileum with exudates over membrane. 
Primary form has unknown cause, so many theories have been put forward like subclinical peritonitis leading to formation of cocoon. Ideopathic form is known as abdominal cocoon. Tu et al. reported a retrospective study of 203 cases of abdominal cocoons where mean age was 33 years, male to female ratio 1.2:1, features of bowel obstruction in $72.4 \%$, abdominal mass in $26.1 \%$ cases. Only $3 \%$ of cases were diagnosed preoperatively. Excision of membrane done in $84.7 \%$, bowel resection in $16.7 \%$, appendectomy in $25.1 \%$ of cases. Post operative recurrent obstruction was found in $11 \%$ and mortality was $5.4 \%$ [3]. It is common in females which may be due to retrograde menstruation causing peritonitis, or cell mediated tissue damage caused by gynecological infections. Brijender et.al reported in 18 cases of abdominal cocoon that more than half of them had abdominal tuberculosis features per-operatively which were later confirmed by investigations post operatively [4]. Developmental conditions like greater omentum hypoplasia mesenteric vessel malformation may also play role in its etiology. Secondary causes are shunt placement for refractory ascitis [5], systemic lupus erythematosis, continuous ambulatory peritoneal dialysis [6], use of povidone iodine in abdominal irrigation [7] and use of practolol [8]. Other causes are abdominal tuberculosis, sarcoidosis, endometriosis, protein S deficiency, dermoid cyst rupture, cirrhosis, liver transplantation, gastrointestinal malignancy, Mediterranean fever, and intraperitoneal chemotherapy.

Clinical features are non specific and may be misleading. They may include recurrent abdominal pain, vomiting, anorexia, weight loss, and episodes of subacute bowel obstruction. X-ray abdomen may show small bowel loops enclosed in cocoon of peritoneum causing proximal bowel dilatation or dilated bowel loop lying in a concertina fashion giving cauliflower sign [9]. CT scan remains gold standard in diagnosis of abdominal cocoon. It demonstrates thickened membrane encasing small bowel loops, thickened bowel loops, tethering or matting of bowel or peritoneal calcification [10]. Fibrosis of mesentery causes clumping and tethering of bowel loops resulting in gingerbread man sign.

A high index of suspicion is required for its diagnosis. Most of cases are not diagnosed preoperatively despite in advancement of imaging and are found at laparotomy. Bo et al. reported that out of 24 cases of abdominal cocoon only four cases were diagnosed by radiological imaging while 20 cases were diagnosed at laparotomy [11]. Differential diagnoses are internal hernias, intusussception, localized peritoneal adhesions. Abdominal cocoon at laparotomy are classified into three types, Type- 1 partial bowel is encased in membrane, Type- 2 entire bowel is encapsulated by membrane, Type-3 entire intestine and other organs like ovary, appendix, caecum, colon are encased by membrane [11].

Treatment can be conservative with corticosteroids, sirolimus or tamoxifen [12] and angiotensin II inhibitors [13] while surgery remains definitive treatment in the form of adhesiolysis. Asymptomatic cases may not require any treatment. Treatment of secondary disease is directed to controlling the primary disease. Surgical treatment includes stripping of membrane, release of small intestine and in some cases enterolysis, small bowel intubation, and bowel resection. We did appendectomy in both cases so as to avoid later complications due to adhesion if appendectomy is required in future. Laparoscopic excision is emerging as treatment of abdominal cocoon [14]. Common complications after surgery are intra-abdominal infections, perforation of bowel and in some cases entero-cutaneous fistula.

\section{Conclusion}

Abdominal cocoon is a rare disease with unknown etiology. A high index of suspicion is required in diagnosing abdominal cocoon. Surgery remains a definitive treatment of abdominal cocoon.

\section{References}

[1] Foo, K.T., Ng, K.C., Rauff, A., Foong, W.C. and Sinniah, R. (1978) Unusual Small Intestinal Obstruction in Adolescent Girls: The Abdominal Cocoon. British Journal of Surgery, 65, 427-430. http://dx.doi.org/10.1002/bjs.1800650617

[2] Sahoo, S.P., Gangopadhyay, A.N., Gupta, D.K., Gopal, S.C., Sharma, S.P. and Dash, R.N. (1996) Abdominal Cocoon in Children: A Report of Four Cases. Journal of Pediatric Surgery, 31, 987-988. http://dx.doi.org/10.1016/S0022-3468(96)90431-5

[3] Tu, J.F., Huang, X.F., Zhu, G.B., Liao, Y. and Jiang, F.Z. (2006) Comprehensive Analysis of 203 Cases with Abdominal Cocoon. Chinese Journal of Gastrointestinal Surgery, 2, 133-135.

[4] Brijendra, S.A. and Shahana, G. (2013) Abdominal Cocoon: A Case Series. International Journal of Surgery, 11, 325328. http://dx.doi.org/10.1016/j.ijsu.2013.02.011

[5] Owtschinnikow, P.J. (1907) Peritonitis Chronic Fibrosaincapsulata. ArchKlinChir, 83, 623-624. 
[6] Kazuyoshi, O., Yoshihiko, O. and Toshinori, O. (2002) Sclerosing Encapsulating Peritonitis: Regional Changes of Peritoneum. Nephron, 92, 481-483. http://dx.doi.org/10.1159/000063290

[7] Keating, J.P., Neill, M. and Hill, G.L. (1997) Sclerosing Encapsulating Peritonitis after Intraperitoneal Use of Povidone Iodine. Australian and New Zealand Journal of Surgery, 67, 742-744. http://dx.doi.org/10.1111/j.1445-2197.1997.tb07126.x

[8] Brown, P., Baddeley, H., Read, A.E., Davis, J.D. and Mcgarry, J. (1974) Sclerosing Peritonitis, an Unusual Reaction to a Beta-Adrenergic-Blocking Drug (Practolol). Lancet, 2, 1477-1481. http://dx.doi.org/10.1016/S0140-6736(74)90218-9

[9] Tombak, M.C., Apaydin, F.D., Colak, T., Duce, M.N., Balci, Y., Yazici, M. and Kara, E. (2010) An Unusual Cause of Intestinal Obstruction: Abdominal Cocoon. American Journal of Roentgenology, 194, W176-W178. http://dx.doi.org/10.2214/AJR.09.3083

[10] Loughrey, G.J., Hawnaur, J.M. and Sambrook, P. (1997) Case Report: Computed Tomographic Appearance of Sclerosing Peritonitis with Gross Peritoneal Calcification. Clinical Radiology, 52, 557-558. http://dx.doi.org/10.1016/S0009-9260(97)80336-4

[11] Bo, W., Hong, B.W., Wei, P.G., Zong, H.Z., Yong, H., Bao, G.H. and Jiang, L.H. (2009) Diagnosis and Treatment of Abdominal Cocoon: A Report of 24 Cases. The American Journal of Surgery, 198, 348-353. http://dx.doi.org/10.1016/j.amjsurg.2008.07.054

[12] Moustafellos, P., Hadjianastassiou, V., Roy, D., et al. (2006) Tamoxifen Therapy in Encapsulating Sclerosing Peritonitis in Patients after Kidney Transplantation. Transplantation Proceedings, 38, 2913-2914. http://dx.doi.org/10.1016/j.transproceed.2006.08.179

[13] Sampimon, D.E., Kolesnyk, I., Korte, M.R., Fieren, M.W., Struijk, D.G. and Krediet, R.T. (2010) Use of Angiotensin II Inhibitors in Patients That Develop Encapsulating Peritoneal Sclerosis. Peritoneal Dialysis International, 30, 656659. http://dx.doi.org/10.3747/pdi.2009.00201

[14] Ertem, M., Ozben, V., Gok, H. and Aksu, E. (2011) An Unusual Case in Surgical Emergency: Abdominal Cocoon and Its Laparoscopic Management. Journal of Minimal Access Surgery, 7, 184-186. http://dx.doi.org/10.4103/0972-9941.83511 
Scientific Research Publishing (SCIRP) is one of the largest Open Access journal publishers. It is currently publishing more than 200 open access, online, peer-reviewed journals covering a wide range of academic disciplines. SCIRP serves the worldwide academic communities and contributes to the progress and application of science with its publication.

Other selected journals from SCIRP are listed as below. Submit your manuscript to us via either submit@scirp.org or Online Submission Portal.
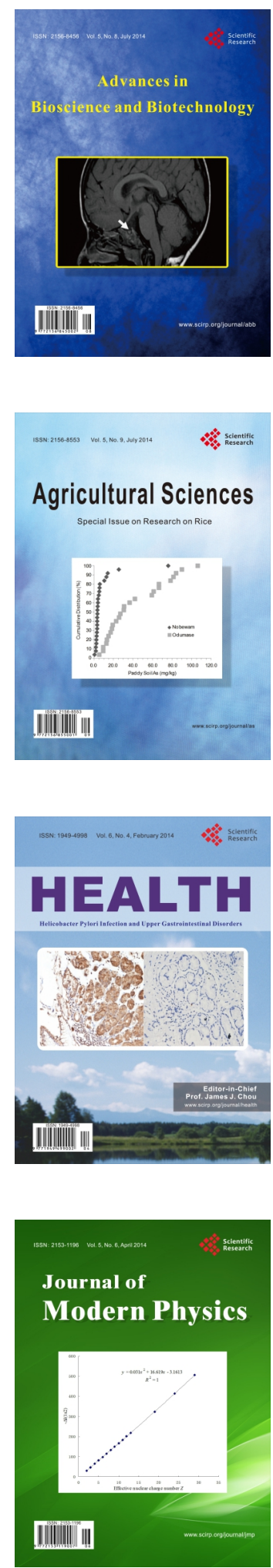
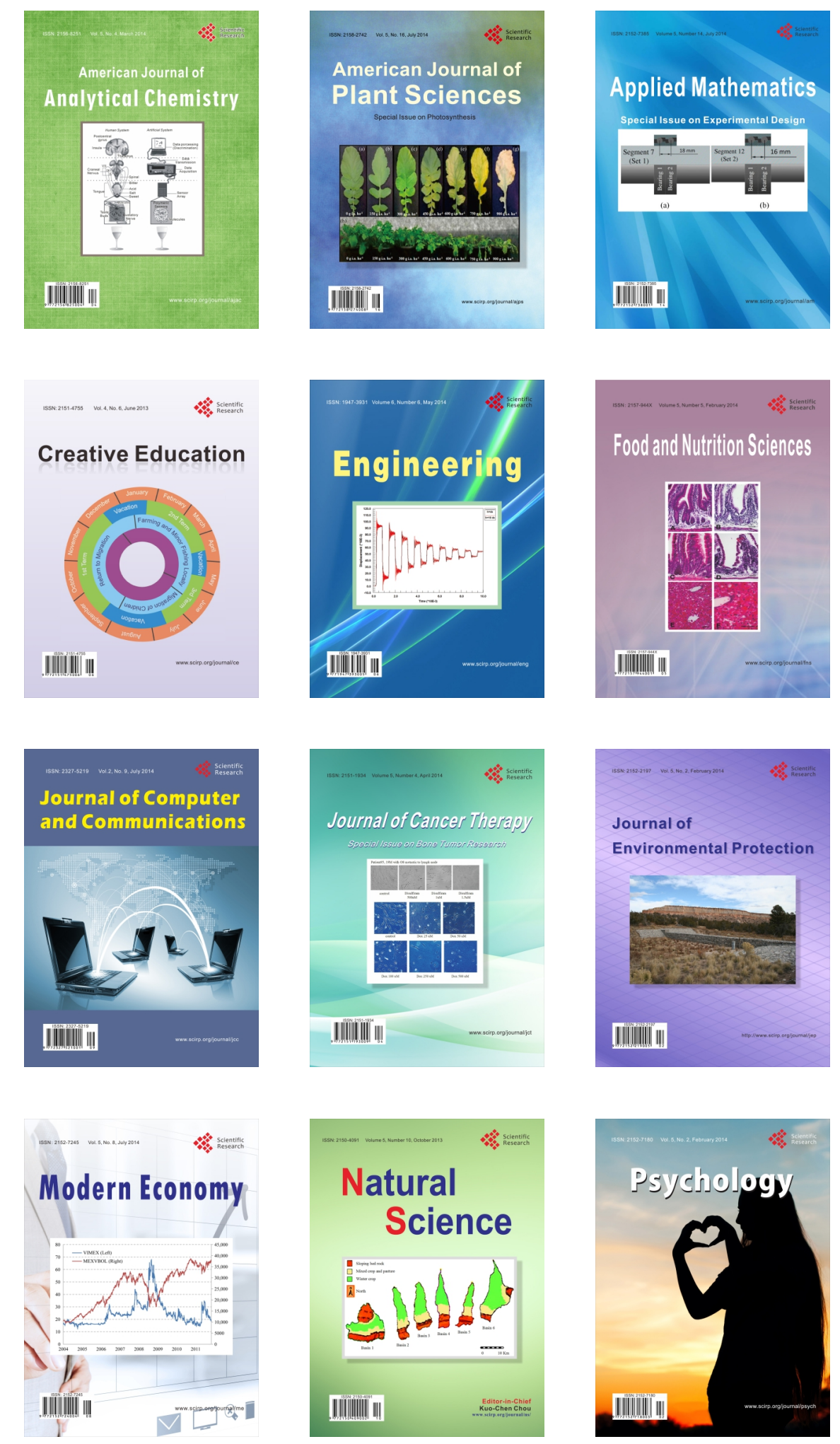